\title{
Post Testicular Sperm Maturational Changes in the Bull: Important Role of the Epididymosomes and Prostasomes
}

\author{
Julieta Caballero, Gilles Frenette, and Robert Sullivan \\ Département d'Obstétrique-Gynéologie, Faculté de Médecine, Centre de Recherche du Centre Hospitalier de \\ l'Université Laval (CHUQ), Université Laval, 2705 Boulevard Laurier, T1-49, Quebec City, QC, Canada G1V 4 G2
}

Correspondence should be addressed to Robert Sullivan, robert.sullivan@crchul.ulaval.ca

Received 19 May 2010; Accepted 3 August 2010

Academic Editor: Ali Honaramooz

Copyright (๑) 2011 Julieta Caballero et al. This is an open access article distributed under the Creative Commons Attribution License, which permits unrestricted use, distribution, and reproduction in any medium, provided the original work is properly cited.

\begin{abstract}
After spermatogenesis, testicular spermatozoa are not able to fertilize an oocyte, they must undergo sequential maturational processes. Part of these essential processes occurs during the transit of the spermatozoa through the male reproductive tract. Since the sperm become silent in terms of translation and transcription at the testicular level, all the maturational changes that take place on them are dependent on the interaction of spermatozoa with epididymal and accessory gland fluids. During the last decades, reproductive biotechnologies applied to bovine species have advanced significantly. The knowledge of the bull reproductive physiology is really important for the improvement of these techniques and the development of new ones. This paper focuses on the importance of the sperm interaction with the male reproductive fluids to acquire the fertilizing ability, with special attention to the role of the membranous vesicles present in those fluids and the recent mechanisms of protein acquisition during sperm maturation.
\end{abstract}

\section{Introduction}

In mammalian species, fertilization is a complex process that occurs in the oviduct of the female reproductive tract [1]. In bovine, since the ovulation is not synchronized with the time of the sperm arrival at the site of fertilization (18-20 hours or more before) and the oocyte fertilization temporal window is narrow, reproductive strategies have been developed in both sexes. The male produces a heterogeneous population of spermatozoa, with different sperm subpopulations available to fertilize an oocyte at any time during the female ovulation window. On the other hand, the female selects and retains attached to the oviductal epithelium the most suitable sperm subpopulation arrived at the oviduct, keeping them with a high fertilizing potential until the ovulation time, when they will be released $[2,3]$. From the male side, the testis is the organ in charged of the continuous production of spermatozoa, and the epididymis is the organ that ensures the production of a heterogeneous sperm population capable of fertilizing an oocyte and also acts as a reservoir of the male gametes.
After completing spermatogenesis and spermiation in the testis, the spermatozoa are not capable of fertilizing an oocyte. The fertilizing ability will be acquired in a temporally controlled manner during different stages towards the encounter with the female gamete: (1) along the transit through the epididymal duct, (2) at the encounter with the seminal plasma during the ejaculation, (3) during the transit through the female reproductive tract, (4) during the interaction with oviductal epithelial cells, and (5) during the interactions with the different female gamete structures. Sperm changes occurring in the male reproductive tract have been defined as maturational changes whereas those occurring in the female counterpart are known as capacitationassociated changes. Epididymal maturation processes need around 10 days to be completed, a relatively long time comparing to the processes that occur from the ejaculation that takes between minutes to hours. This is an indicator of the level of complexity in the events that take place in the epididymis.

During maturation, the spermatozoa undergo many biochemical and morphological modifications. Some of 
them include the addition of epididymal proteins to the maturating sperm, a process that has been specially studied [4-6], and also some molecular reorganizational changes at the cell membrane level. It is interesting to note that those are common mechanisms between maturation and capacitation events [7]. Among them, the movement of some enzymes [8, 9], membrane lipids [10], and cholesterol [11] can be cited. In addition, changes in membrane fluidity as a consequence of cholesterol efflux and protein dissociation from raft domain seems to be also a mechanism that occurs both in capacitation $[12,13]$ and in the maturational processes occurring at the time of ejaculation [14].

Since the spermatozoa must complete all those physiological processes to be able to fertilize an oocyte, a better understanding of the mechanisms involved has a great impact in the development of bovine reproductive biotechnologies. This paper focuses on the events associated with the acquisition of the sperm maturation along the epididymal duct and the postejaculatory sperm modifications with emphasis on the role of the membranous vesicles present in the epididymal fluid (epididymosomes) and seminal plasma (prostasomes) on those processes.

\section{The Epididymis}

The epididymal duct is a long convoluted tubule tightly coiled over the testicular surface that connects the efferent ducts to the vas deferens embryologically originated from the anterior Wolffian or mesonephric duct [15]. Three different regions are anatomically distinguished: the head (caput), the body (corpus), and the tail (cauda) (Figure 1) [16]. All along the epididymal tubule, the lumen is bordered by an epithelium that is very active in protein synthesis and secretion [17] under androgenic stimulation [18, 19]. The pseudostratified epithelium is composed mainly of principal $(85 \%)$ and basal cells, accompanied by other specialized cells distributed in a segment-specific manner including apical, narrow, clear, and halo cells. Between important known functions of these cells, secretion, absorption, endocytosis, acidification of the luminal fluid, immune defense, phagocytosis, and antioxidant production can be mentioned [20]. The epithelium forms an epididymal barrier by the presence of tight junction between epithelial cells [20]. Fluid composition in each epididymal segment shows great variability from one epididymal segment to the other $[21,22]$ as well as the pattern of gene expression $[23,24]$.

The epididymis is the organ responsible for the sperm transport, concentration, storage, and maturation. The epididymal sperm maturation function involves the acquisition of the forward motility and the fertilizing ability [4]. The latter is defined as the acquisition of the many physiological properties by the spermatozoon including the ability to bind the zona pellucida, an extracellular glycoprotein coat surrounding the oocytes, and to fuse with the egg plasma membrane. The fertilizing ability is acquired by the spermatozoa during the epididymal transit, since it has been demonstrated that spermatozoa collected from the proximal segments are unable to fertilize an oocyte in artificial insemination or in vitro fertilization procedures

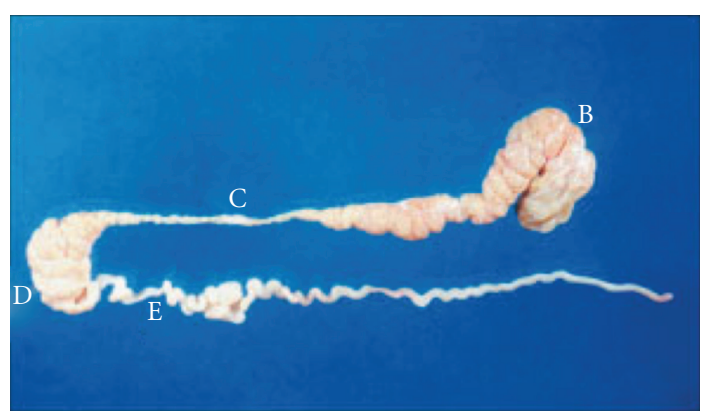

Figure 1: Photography taken from a bull epididymis. Different anatomical sections are identified: caput (b), corpus (c), and cauda (d). Vas deferens is also indicated (e). Reproduced from [16] with permission of the Editorial.

[25] but, in the majority of species, they start to acquire fertilizing potential in the middle corpus [26].

When spermatozoa reach the elongated spermatid stage in the testis, their DNA starts to be progressively condensed, and as a consequence, the DNA transcription will be arrested. At the time the spermatozoa initiate the epididymal transit, the synthesis of new proteins is then at a very low range. Because of this, the sperm maturational process depends on the sequential interactions of sperm with different intraluminal fluids [27].

During this transit, spermatozoa undergo many biochemical modifications including the nucleus chromatin condensation, increases in total surface negative charges and in disulfide bounds, changes in the plasma membrane protein and lipid composition (phospholipids composition, cholesterol/phospholipids ratio), relocalization of surface antigens, elimination and modifications of surface proteins $[5,28]$, structural modifications of the cytoplasmic perinuclear theca (PT) [29], and the ability to respond to hypoosmotic stress [30].

Spermatozoa are transported through the caput and corpus epididymal regions by continuous peristaltic contractions originated in the smooth muscles present in the wall of the duct, whereas the cauda is maintained quiescent unless it can be stimulated to contract. The cauda is the main region responsible for the sperm storage and survival [31]. In bulls and stallions, the number of sperms stored in the cauda is sufficient for ten successive ejaculates [32]. The epididymal cauda environment also keeps spermatozoa in a metabolic quiescence by preventing premature activation.

The epididymal gene expression and secretion are regulated by the intraluminal and circulating androgens [33, 34]. Those androgens come from the enzymatic reduction of the testicular testosterone in the epididymal proximal regions [35]. Estrogens synthesized by Leydig cells [36] and epididymal spermatozoa [37] have also a function in the epididymis, they are involved in water reabsorption specially in the proximal regions [36, 38-40]. Not only hormones influence the epididymal function but also the scrotal temperature [41-44], between 35 and $37^{\circ} \mathrm{C}$ in the bull [45], and the presence of epididymal spermatozoa in close contact with the epididymal cells [44]. 


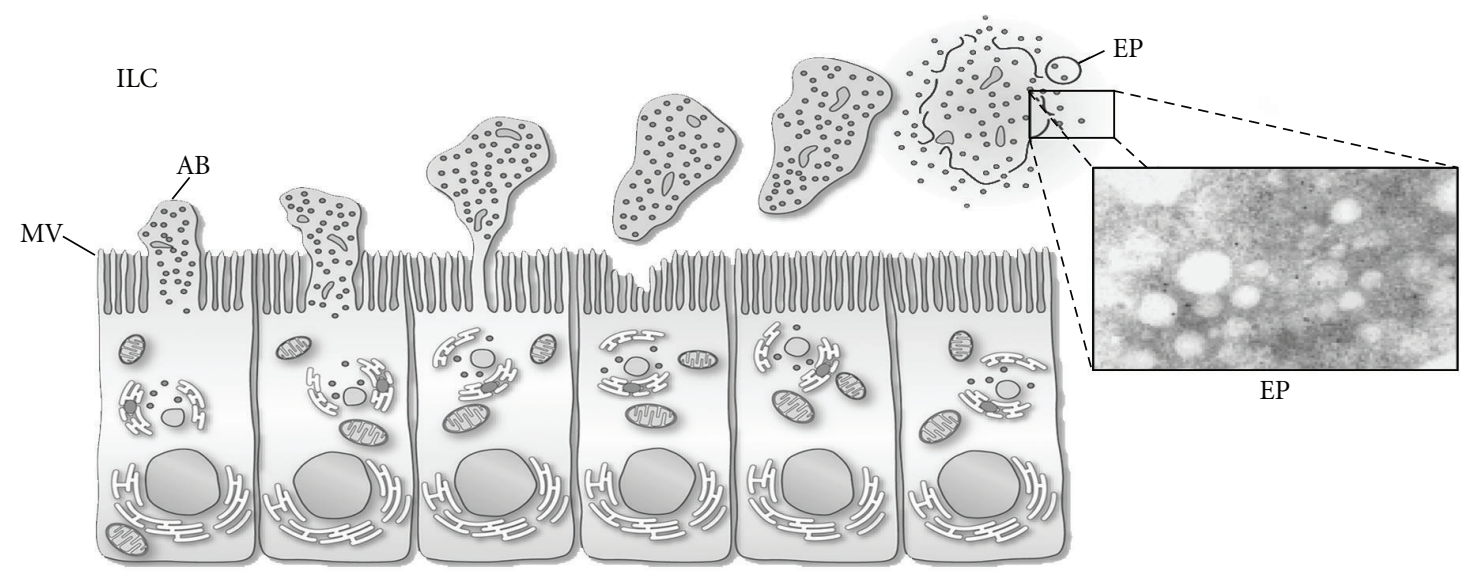

FIGURE 2: Schematic representation of apocrine secretion in principal cells of the epididymis. The inset shows electron micrograph of epididymosomes. AB, apical bleb; EP, epididymosomes; ILC, intraluminal compartment; MV, microvilli. Reproduced from [32] with permission of the Editorial.

\section{Epididymal Fluid and Epididymosomes}

Different electrolytes and organic compounds were identified in bull epididymal fluid. From proximal to distal, there is a decrease in sodium and chloride with a consequent increase in organic constituents [46].

Since there is a variation in the gene expression and the resultant protein expression profile along the epididymal tubule $[5,23]$, the spermatozoa must undergo a sequential maturational process by interaction with different segment intraluminal fluid and its macromolecules [23]. As it was mentioned above, the male gamete undergoes many modifications during the epididymal transit in order to acquire the fertilizing ability $[5,28]$, and protein acquisition is one of the most studied aspects [6]. The acquired proteins can behave as coating [47], bound trough electrostatic interactions, or integral plasma membrane proteins [6]. Those integral proteins are mainly glycosylphosphatidylinositol (GPI) anchored to sperm plasma membrane [48] or integral proteins that lack an $\mathrm{N}$-terminal signal peptide in their deduced amino acid sequence $[49,50]$, suggesting that these proteins cannot be translocated to the endoplasmic reticulum. On the other hand, it has been demonstrated that there are epididymal proteins that can be also incorporated to the sperm intracellular subcompartments [51-53]. All together these evidences suggest that besides the existence of a merocrine secretion mechanism, by which the secreted proteins are expected to be soluble in the intraluminal fluid, in the epididymal epithelium, there is another unusual mechanism of secretion [54].

In 1985, Yanagimachi [55] described for the first time the presence of membranous vesicular structures in the Chinese hamster epididymal lumen, and he suggested a possible sperm plasma membrane cholesterol transport function. Later, the same structures were described in rat $[51,56]$, bovine [57-59], and hamster [55, 60].

Membranous vesicles are secreted to the intraluminal compartment by apocrine secretion (Figure 2) [32]. This type of secretion is characterized by the formation of blebs in the apical pole of the epithelial cell that are detached later, probably by the involvement of cytoskeleton proteins like actin [61]. Those structures contain selected organelles and vesicles of various sizes, and there is one hypothesis that argues that upon detachment they undergo fragmentation [20]. This process was first described in different tissues in the rat [62]. Later on, it was described also in epididymal epithelium of different species (monkey [63], bovine [64], mouse [65], and cat [66]). Recent studies have confirmed the existence of this specialized type of secretion $[61,67]$.

As a result of fragmentation of the apical blebs, these membranous vesicles called epididymosomes are released in the epididymal intraluminal compartment. These membranous particles have a diameter of 50 to $500 \mathrm{~nm}$ and a highly complex protein pattern composition $[54,68]$. Some of these proteins are important in the acquisition of sperm-fertilizing ability [57], whereas others have been proposed to modulate the acquisition of the sperm forward motility $[16,69]$, to protect sperm against reactive oxygen species [70], or to be involved in the elimination of defective spermatozoa [58].

\section{Epididymosomes and Epididymal Sperm Protein Transfer}

In different species, some of the proteins present in the spermatozoa during their transit through the epididymal duct have been identified in the epididymosomes. Those proteins have a wide range of functions. CD52 (HE5) is a GPI-anchored lymphocyte surface antigen involved in the modulation of immunological fertility in human, cynomologus monkey, and rat [71, 72]. The Murine Sperm Adhesion Molecule 1 (SPAM1)/PH-20 is a GPI-anchored protein (one of testicular and one of epididymal origin) that plays a role in sperm-egg cumulus complex interaction [73]. SPAM1 homologous has been reported in human [74], cynomologus monkey [75], bovine [76, 77], and rat [78]. GPX5, a member of the glutathione peroxidase family, 
is added to the spermatozoa in the proximal epididymal regions and participates in the sperm protection against oxidative stress $[70,79]$. Membranous vesicles found in the bovine epididymal caput were found responsible for the transfer of ubiquitin to the spermatozoa [58], suggesting that this mechanism can be involved in the elimination of defective spermatozoa. More recently, ADAM7, an epididymalexpressed disintegrin and metalloproteases lost in sperm from ADAM2 or ADAM3 knock-out mice [80] with critical roles in the fertilization process [81], was demonstrated to be added to the spermatozoa during the epididymal transit by epididymosomes [82].

P26h is a GPI-anchored protein transferred to the hamster spermatozoa by epididymosomes involved in the acquisition of zona pellucida binding ability [83]. It is localized in the plasma membrane covering the sperm acrosomal region [60] and participates in sperm-zona pellucida interactions [84]. Its orthologs have been described in human (P34H [85]), mice (P25m [86]), bovine (P25b [87, 88]), and cynomologus monkey (P31m [89]) with the same subcellular localization. In the bovine, the amount of P25b in spermatozoa increases from the corpus to the cauda epididymal regions and the protein seems to be added by epididymosomes since the pattern of expression in those structures that maintain the same profile and coincubation experiments revealed that they are able to transfer it to spermatozoa [57]. These observations are in accordance with those observed in the hamster model with its ortholog p26h [60].

4.1. Mechanism of Interaction between Epididymosomes and Spermatozoa. In the bull, the proteins associated to the epididymosomes represent only a low proportion of all the proteins found in the epididymal fluid, and this association is characterized by being very strong [50]. From these proteins, only a selected group can be transferred to the sperm suggesting that the epididymosomes are not fused to the sperm plasma membrane but transfer selected molecules in a regulated manner. Interestingly, those proteins are transferred to the midpiece and/or the acrosomal cap [59], regions with important functions in motility and female gamete interactions, respectively. Indeed, P25b was localized in the acrosomal cap [87] as well as its ortholog P26h, involved in the sperm-zona pellucida interactions [84].

The amount of biotinylated cauda epididymal proteins transferred to the bovine caput spermatozoa in in vitro coincubation experiments increases with the time until reaching a plateau after 120 to 150 minutes [59]. After this incubation time, the addition of unbiotinylated proteins to the coincubation experiments is unable to displace the already acquired biotinylated proteins, suggesting that the transferred proteins are tightly bound to the sperm membrane [69]. The transfer is more efficient at physiological epididymal environment conditions $[46,90,91]$ : temperature of $37^{\circ} \mathrm{C}, \mathrm{pH}$ of 6.0 to 6.5 , and in presence of zinc [59]. In accordance with these observations, the optimum $\mathrm{pH}$ for the transfer of $\mathrm{P} 25 \mathrm{~b}$ was also slightly acidic [57].

Further studies demonstrated that epididymosomes collected from caput or cauda epididymal fluid have a different protein composition. Although they have many proteins in common, as beta-actin, aldose reductase, and MIF, there are many others whose expression is restricted to one or the other population. As an example, HSPA5 is more expressed in caput, and P25b was only found in cauda epididymosomes [69]. In addition, biotinylated proteins associated with caput and cauda epididymosomes showed differences, suggesting that they have a distinctive group of proteins exposed in the membrane surface and, therefore, different proteins to interact with the male gamete and in a different way. This idea is supported by the fact that whereas caput epididymosomes transfer a different pattern of biotinylated proteins to the caput than to the cauda spermatozoa, cauda epididymosomes can transfer the same biotinylated protein pattern to both sperm populations. Thus, it was demonstrated that caput epididymosomes are unable to compete with cauda epididymosomes in coincubation experiments [69]. In summary, it is proposed that each epididymosome population has a different protein composition, capable to transfer a different set of protein to the maturating spermatozoa and interacting with them in a different way.

Those interactions could be regulated by the presence of different functional membrane domains. It is well known that the plasma membrane of both somatic [92] and sperm cells [93] is compartmentalized in different structures. Cholesterol- and sphingolipid-enriched detergentresistant membrane domains or "rafts" are special membrane domains with an important role in the compartmentalization of specific lipids and proteins, driving also cell signal transduction and vesicular trafficking events [94]. These microdomains are enriched in GPI-anchored and transmembrane signaling molecules like protein tyrosine kinases $[95,96]$. In the bull epididymal spermatozoa, it has been reported that some proteins are excluded from rafts (aldose reductase and MIF) and others are detected in rafts domains (P25b and AK1). However, along the epididymal transit, they can undergo important compositional modifications [97] and a topographical reorganization of different components $[10,11]$. This is the case of AK1 that, distally in the epididymal duct, can be found equally associated to the raft and nonraft sperm plasma membrane domains [14]. Based on these findings, it is proposed that the raft domains have a role in the mechanism of protein transfer from the epididymosomes to the spermatozoa. In agreement with this hypothesis, it was demonstrated that raft and nonraft domains also exist in cauda epididymosomes and that the raft surface-associated $\mathrm{P} 25 \mathrm{~b}$ protein can be transferred to the same localization and membrane domain to the caput spermatozoa [98].

As it was discussed above, there exist different epididymosomes populations according to the epididymal segment where they are secreted. It has been also reported the presence of two different populations of vesicles in the rat cauda epididymal fluid according to their ultrastructure and enzymatic composition [99]. In bovine, it has also been recently reported the existence of two different cauda epididymosomes populations, not differentiated by their size but by their density, protein and lipid composition, and ultrastrutural appearance. The low-density population 
is characterized by having a higher cholesterol/phospholid ratio than the high-density one. They also have a higher amount of proteins associated to lipid rafts, like $\mathrm{P} 25 \mathrm{~b}$, in contrast to the high-density population, that are enriched in beta-actin. Despite these differences, they are capable of transferring the same biotinylated protein pattern, suggesting that those differences could have played a role in other aspects of the interaction mechanisms [100].

\section{The Role of Epididymis in Sperm Survival and the Acquisition of Sperm Motility}

Under androgen control, the epididymal epithelial cells secrete many factors to the lumen of the tubule involved in the spermatozoa survival and storing processes [19]. It has been described that the cauda epididymal secretions have the ability to store sperm cells for several days maintaining their fertilizing ability [31]. It was observed that spermatozoa establish specific interactions with epididymal principal cell cultured in vitro [101], including the observation of a high percentage of spermatozoa anchored to the epididymal cell membranes [102]. In bovine, the presence of cauda epididymal cells or their secretions can improve the sperm motility [102-104]. Those effects were also observed in the human model [101, 105]. However, the same response is observed when spermatozoa are coincubated with cells from different tissue origin, including oviductal epithelial cells $[106,107]$. Studies carried out in bovine demonstrated that several protease inhibitors [108] and a $42-\mathrm{kDa}$ protein are secreted and are capable of maintaining the sperm motility. The later is adsorbed to the sperm surface during incubation with epididymal cells culture medium, and this protein was identified as the bovine estrogen sulfotransferase (EST). This protein was also found in the acrosomal region of the hamster spermatozoa, acquired along the epididymal transit [109]. One of the possible functions suggested was to inhibit the activation of the acrosomal protease acrosin $[109,110]$.

Estrogen sulfotransferase (EST) is a cytosolic enzyme that catalyzes a specific sulfonation with high substrate affinity for estrogens (estrone and estradiol) [111]. It is present in the acrosomal region of epididymal caput spermatozoa as well as in caput epididymal tissue and epididymosomes. Recombinant EST was able to add a sulfate group to cholesterol on epididymal spermatozoa. Even EST has a high affinity for estradiol, the concentration of this compound decreases dramatically in the proximal segments of the epididymis, favoring other sterols present in the sperm membrane to be sulfated [112].

It has been demonstrated that other molecules probably involved in the regulation of the sperm motility are transferred from epididymosomes to spermatozoa; this is the case for enzymes belonging to the polyol pathway and the cytokine, macrophage inhibitor factor (MIF).

The enzymes aldose reductase (AKR1B1) and sorbitol dehydrogenase $(\mathrm{SODH})$ are members of the polyol pathway and their presence has been reported in rat [113], human [114], and bovine epididymis [16]. AKR1B1 is an enzyme that reduces glucose into sorbitol using NADPH as an electron donor. On the other hand, SODH can oxidize sorbitol into fructose by using NAD as an electron acceptor [115]. Since both, sorbitol and fructose, are energy sources for the spermatozoa [116], it is proposed that those molecules could play a role in the modulation of sperm motility. Both proteins have been identified in the spermatozoa and the principal cells of the epididymal epithelium and epididymosomes, suggesting that they are being secreted by apocrine secretion. In fact, this statement is enforced by the absence of the signal peptide in AKR1B1 sequence [50]. Aldose reductase expression and activity are maximal in the proximal and middle segments of the epididymis and decreasing to distal [50] while for SODH are higher in the proximal and distal segments of the epididymis compared to the middle segment [16]. Interestingly, the optimal $\mathrm{pH}$ for aldose reductase maximal enzymatic activity is 6.5 , the physiological $\mathrm{pH}$ of the epididymal milieu, whereas for SODH, the enzymatic activity is higher at $\mathrm{pH} 7.0$, closer to the $\mathrm{pH}$ that the spermatozoa encounter after ejaculation. Those observations suggest that in proximal segments the polyol pathway could collaborate to maintain a sperm transient immobilization. This could be explained by the hyperosmolarity of the epididymal milieu generated by sorbitol and the deprivation of energy sources to the sperm intracellular compartment, since sorbitol is poorly permeable to the sperm plasma membrane. But at the end of the epididymal transit, sorbitol is oxided in fructose, a permeable energy source that now can be used by spermatozoa.

Macrophage migration inhibitory factor (MIF) is a Tcell cytokine [117], whose presence has been also reported in many other tissues including the male reproductive tract [50, 51]. In the rat, it was found in small vesicles secreted by the epididymal epithelium that interact with the spermatozoa in the epididymal lumen. Later in the epididymal transit, MIF was found associated with the sperm dense fibers suggesting a role of MIF in the sperm motility acquisition [51]. In the bovine, MIF is also present in the epididymal spermatozoa and epididymosomes. The localization of MIF in the principal cells of the epididymal epithelium and the lack of the signal peptide in the MIF sequence reinforce the idea that MIF is secreted in an apocrine way. Another possible role for MIF in the acquisition of the sperm motility is the fact that MIF has a thiol-protein oxydoreductase catalytic property that can participate in the thiol status of the maturating epididymal spermatozoa [51].

The control of sperm motility is a complex process involving different pathways. Protein phosphorylation is another mechanism implicated on the motility startup. The signaling kinase, glycogen synthase kinase-3 (GSK-3), regulated by serine and tyrosine phosphorylation [118], and the protein phosphatase $\mathrm{PP} 1 \gamma 2$ are present in the epididymal spermatozoa and are critical for the regulation of sperm motility and fertility [119].

\section{Seminal Plasma Proteins and Prostasomes}

Seminal plasma is composed of mixed secretions of the male accessory reproductive glands. Vesicular structures similar to epididymosomes have been also found in the seminal plasma. Those structures were first described in the human 
semen as a prostate secretion, and due to this, they were called prostasomes $[120,121]$. Prostasomes-like vesicles were found in seminal plasma from many other species [122125], including bovine [57]. Whereas in bovine, those are secreted by seminal vesicles [126]; in human, seminal vesicles do not seem to be the accessory gland responsible for the production of this secretion [127]. Those particles, as epididymosomes, have also a diameter of 50 to $500 \mathrm{~nm}$, a cholesterol/phospholipid ratio of 2 , a high content of sphingomyelin, and many proteins associated with them, like many enzymes [128], aldose reductase, P25b, MIF, and PDC109 [14]. Recently, the presence of chromosomal DNA in those structures was demonstrated, suggesting its possible transfer to the spermatozoa [129]. However, the mechanism by which they are produced is slightly different. They are formed in the cytoplasm of the prostatic cells in storage vesicles and then, by exocytosis, their content is released into the extracellular lumen [121]. It has been reported that the fusion of prostasomes isolated from human semen to the spermatozoa is favored at an acidic $\mathrm{pH}$ [130].

Their functions have been better studied in humans. It is well known that prostasomes have immunosuppressive activity via protection against complement attack [131-133], increase the sperm motility $[134,135]$, and have a role in the sperm capacitation process [136] and in the stabilization of the sperm plasma membrane [54].

\section{Changes in the Spermatozoa at the Time of Ejaculation}

Once in the female reproductive tract, spermatozoa start to undergo changes directed to prepare the male gamete to fertilize the oocyte. Those processes involve the formation of the oviductal epithelium reservoir, designed to keep the spermatozoa with fertilizing ability until the moment of the ovulation, the molecular changes that occur to display the hyperactivated motility, and the capacitating associated changes that prepare the spermatozoa to penetrate the female gamete.

At ejaculation, the spermatozoa are mixed with the seminal plasma components. In the bovine, the seminal vesicles secrete a family of proteins called bovine seminal plasma or BSP proteins. They contain two fibronectin type II domains in tandem [137-139] that bind to choline phospholipids [140] on the sperm membrane and stimulate their phospholipid and cholesterol efflux [141]. This is one of the first events that occur during capacitation [142]. Cholesterol efflux alters the lipid raft stability and the distribution of these domains [93, 143] and, as a consequence, proteins associated with lipid rafts are also disarranged [12].

Bovine cauda epididymal spermatozoa have proteins associated to rafts (P25b and AK1) and nonrafts domains (aldose reductase and MIF) [14]. When the localization of those proteins is evaluated in spermatozoa recovered from 60-min postejaculated semen, P25b and AK1 proteins are excluded from the raft domains. Whereas AK1 is displaced to nonrafts domains as early as 15 minutes after ejaculation, P25b completes its migration after 30 minutes. Those changes were accompanied by a decrease in the cholesterol content in ejaculated compared with cauda epididymal spermatozoa. Incubation of cauda epididymal spermatozoa with seminal plasma without prostasomes or metabolites could reproduce the same results, but not with the BSP proteins. PDC-109, previously described as a protein responsible for the cholesterol efflux in the bovine sperm at the ejaculation, was capable of dissociating the P25b from the raft domains after 4 hours of incubation. Instead, Niemann-Pick C2 (NPC2), also found in the seminal plasma of various species $[144,145]$, was able to induce those changes earlier. The ejaculated spermatozoa plasma membrane reorganization could have an important role in the correct positioning of molecules involved with the attachment to the oviductal epithelium and female gamete interactions. In fact, $\mathrm{AK}$ activity is important for biosynthesis of ATP and then for flagellar motility [146], and P25b was demonstrated to be a bull fertility marker [87].

\section{Molecular Markers of Bull Fertility}

All the maturational processes that the spermatozoa undergo once they leave the testis prepare them to fertilize the oocyte. As it was discussed above, in many of them, like protein acquisition and molecular reorganization, epididymosomes and prostasomes are involved. Since those mechanisms have been well studied, their occurrence may be associated with sperm maturation and the fertilizing ability acquisition. This is the case of P25b, involved in the sperm maturation, since it is a protein acquired by the spermatozoa in the epididymis by epididymosomes transfer [57] and in the acquisition of fertilizing ability, since it is present in a higher amount in bulls with high fertility rates compared to those that are subfertile [87]. This fact is confirmed for its role in human $(\mathrm{P} 34 \mathrm{H})$, whose expression was decreased in a significant proportion of men investigated for male infertility [85, 147].

Comparative analysis of the protein composition of accessory glands fluid [148, 149], cauda epididymal fluid [150], and ejaculated spermatozoa [151] between bulls with high and low fertility rates allowed to associate some other proteins to the sperm fertilizing ability whose mechanism of acquisition has not been described yet.

In the accessory sex glands fluid of high fertility rates bulls, it was found a higher amount of osteopontin and phospholipase A2 than in the fluids coming from low fertility rates bulls [148]. Osteopontin is a protein found in the postacrosomal region of cauda epididymal and ejaculates spermatozoa with a role suggested in fertilization and the blocking of the polyspermy [152], and PLA2 is present in the bull sperm plasma membrane [153], and it is related to acrosome reaction events [154], sperm-egg fusion [155, 156], and probable implications in sperm motility [157]. On the other hand, a lower amount of spermadhesin Z13 was found the protein extracts from those bulls, with a variable association of BSP5 expression. Spermadhesin Z13 is a protein with dual effects on bovine sperm motility, stimulating at average concentrations, but inhibitory at high levels [158]. On the contrary, a member of the spermadhesin protein family from the boar seminal plasma, PSP-I, has been proposed as candidate fertility marker [159]. BSP5 facilitates fertilization 
by cholesterol efflux induction, but higher amounts became detrimental to fertility [160]. BSP5 was demonstrated to have an inhibitory activity on PLA2 [161]; probable explanation for the noncorrelated results is observed.

Fertility-associated antigen (FAA) is a heparin-binding protein (HBP) whose presence was associated with high fertility in bulls [149]. The protein is detected in seminal vesicle, prostate accessory glands, and sperm membranes.

In the cauda epididymal fluids, $\alpha$-L-fucosidase and cathepsin D were more predominant in high-fertility bulls, while 3 isoforms of Prostaglandin D synthase (PGDS) were associated to low-fertility scored bulls [150]. $\alpha$-L-fucosidase may participate in the modification of carbohydrate moieties of sperm membrane proteins during epididymal transit, and it was absent in seminal plasma of bulls with elevated percentage of abnormal sperm [162]. Cathepsin D is synthesized mainly in caput and corpus epididymal regions of the stallion [145] and may participate in the proteolytic remodeling of membrane components of sperm during epididymal transit. The role of PGDS is not clear, but it was suggested that they act on polyunsaturated fatty acid in the sperm [163], regulating membrane fluidity [164].

D'Amours et al. [151] found three proteins more abundant in sperm extracts from low fertility rates bulls: Tcomplex protein 1 subunits 3 and q (CCT5 and CCT8), proteasome subunit a type-6 (PSMA6), two isoforms of epididymal sperm-binding protein E12 (ELSPBP1) and BSP1, and two proteins significantly more associated to high-fertility bulls: adenylate kinase isoenzyme 1 (AK1) and phosphatidylethanolamine-binding protein 1 (PEBP1). CCTs and AK1 explained $64 \%$ of the fertility scores. CCTs are members of the class II chaperonins, and after working during spermatogenesis it would be discarded in residual bodies at spermiation [151]. PSMA6 is part of the proteasome multicatalytic protease that degrades polyubiquitinated proteins [151], and its presence has been associated with sperm ubiquitination and DNA defects in bulls [151]. ELSPBP1 has epididymal origin [165] with structural similarities to BSPs, suggesting that those proteins could stimulate lipid efflux and destabilize the membranes, reason supported by the finding of ELSPBP1 and BSP1 in immotile but still alive sperm subpopulation. AK1 is an enzyme acquired during the epididymal transit with functions in sperm motility $[146,166]$, and PEBP1 is a GPI-anchored receptor [167] with inhibitory effect on sperm capacitation [168], probably the explanation for its negative correlation with BSP1.

\section{Conclusion}

The secretion of membranous vesicles by the epididymal and accessory glands epithelia to the epididymal fluid or seminal plasma, respectively, is one of the mechanisms by these cells are capable to control the sperm posttesticular maturation. These processes occur in a time and tissue sequential manner under hormonal control. The experimental data summarized in this paper support the important role of this mechanism in the acquisition of the fertilizing ability by the spermatozoa.

The possibility of epididymosomes purification and the demonstration of its ability to transfer proteins under in vitro conditions to the maturating spermatozoa open a possibility of its uses in reproductive biotechnologies like semen freezing or in vitro fertilization.

It is also known that processes associated to cryopreservation can reduce sperm fertility by causing several damages and capacitating-associated events on them [169171]. Lessard et al. [88] demonstrated that the loss of P25b during the cryopreservation procedures could be one of the responsible events that cause a decrease in the bull semen fertility. In this case, coincubation of spermatozoa with epididymosomes could be thought as a rescuing therapy.

Since some of the proteins acquired by the spermatozoa during the maturational processes have been already described, these can be used as fertility markers, having the possibility to select male with higher fertility performance.

All together, it can be concluded that the membranous vesicles have an important role in the sperm physiology and it is, at the moment, the main process involved in the acquisition of the sperm fertilizing ability. Its use in reproductive technologies is still an area to explore.

\section{Acknowledgment}

The authors' work described in this paper was supported by "Natural Sciences and Engineering Research Council" of Canada grants to R. Sullivan.

\section{References}

[1] R. Yanagimachi, "Fertilization in mammals," Tokai Journal of Experimental and Clinical Medicine, vol. 9, no. 2, pp. 81-85, 1984.

[2] R. H. Hunter and I. Wilmut, "Sperm transport in the cow: peri-ovulatory redistribution of viable cells within the oviduct," Reproduction Nutrition Developpement, vol. 24, no. 5 A, pp. 597-608, 1984.

[3] R. H. F. Hunter, "Sperm release from oviduct epithelial binding is controlled hormonally by peri-ovulatory graafian follicles," Molecular Reproduction and Development, vol. 75, no. 1, pp. 167-174, 2008.

[4] T. G. Cooper and C. H. Yeung, "Sperm maturation in the human epididymis," in The Sperm Cell. Production, Maturation, Fertilization, Regeneration, pp. 72-107, Cambridge University Press, Cambridge, UK, 2006.

[5] P. D. Cuasnicu, D. Ellerman, D. Busso, V. DaRos, and M. Morgenfeld, "Changes in sperm proteins during epididymal maturation," in The Epididymis. From Molecules to Clinical Practice, pp. 389-404, Plenum Press, New York, NY, USA, 2002.

[6] T. G. Cooper, "Interactions between epididymal secretions and spermatozoa," Journal of Reproduction and Fertility, vol. 53, pp. 119-136, 1998.

[7] D. E. Wolf and J. K. Voglmayr, "Diffusion and regionalization in membranes of maturing ram spermatozoa," Journal of Cell Biology, vol. 98, no. 5, pp. 1678-1684, 1984.

[8] A. Zanich, J. C. Pascall, and R. Jones, "Secreted epididymal glycoprotein 2D6 that binds to the sperm's plasma membrane is a member of the beta-defensin superfamily of poreforming glycopeptides," Biology of Reproduction, vol. 69, no. 6, pp. 1831-1842, 2003.

[9] S. A. Belmonte, P. S. Romano, and M. A. Sosa, "Mannose-6phosphate receptors as a molecular indicator of maturation 
of epididymal sperm," Archives of Andrology, vol. 48, no. 1, pp. 53-63, 2002.

[10] C. A. Wolfe, P. S. James, A. R. Mackie, S. Ladha, and R. Jones, "Regionalized lipid diffusion in the plasma membrane of mammalian spermatozoa," Biology of Reproduction, vol. 59, no. 6, pp. 1506-1514, 1998.

[11] Y. Christova, P. James, A. Mackie, T. G. Cooper, and R. Jones, "Molecular diffusion in sperm plasma membranes during epididymal maturation," Molecular and Cellular Endocrinology, vol. 216, no. 1, pp. 41-46, 2004.

[12] S. B. Sleight, P. V. Miranda, N.-W. Plaskett et al., "Isolation and proteomic analysis of mouse sperm detergent-resistant membrane fractions: evidence for dissociation of lipid rafts during capacitation," Biology of Reproduction, vol. 73, no. 4, pp. 721-729, 2005.

[13] N. L. Cross, "Reorganization of lipid rafts during capacitation of human sperm," Biology of Reproduction, vol. 71, no. 4, pp. 1367-1373, 2004.

[14] J. Girouard, G. Frenette, and R. Sullivan, "Seminal plasma proteins regulate the association of lipids and proteins within detergent-resistant membrane domains of bovine spermatozoa," Biology of Reproduction, vol. 78, no. 5, pp. 921931, 2008.

[15] A. Joseph, H. Yao, and B. T. Hinton, "Development and morphogenesis of the Wolffian/epididymal duct, more twists and turns," Developmental Biology, vol. 325, no. 1, pp. 6-14, 2009.

[16] G. Frenette, C. Lessard, and R. Sullivan, "Polyol pathway along the bovine epididymis," Molecular Reproduction and Development, vol. 69, no. 4, pp. 448-456, 2004.

[17] L. Hermo, J. Wright, R. Oko, and C. R. Morales, "Role of epithelial cells of the male excurrent duct system of the rat in the endocytosis or secretion of sulfated glycoprotein-2 (clusterin)," Biology of Reproduction, vol. 44, no. 6, pp. 11131131, 1991.

[18] P. S. Cuasnicu, F. G. Echeverria, A. Piazza, and J. A. Blaquier, "Addition of androgens to cultured hamster epididymis increases zona recognition by immature spermatozoa," Journal of Reproduction and Fertility, vol. 70, no. 2, pp. 541-547, 1984.

[19] B. Robaire and R. S. Viger, "Regulation of epididymal epithelial cell functions," Biology of Reproduction, vol. 52, no. 2, pp. 226-236, 1995.

[20] L. Hermo and B. Robaire, "Epididymal cell types and their functions," in The Epididymis, from Molecules to Clinical Practice, pp. 81-102, Kluwer Academic/Plenum Publishers, New York, NY, USA, 2002.

[21] J. L. Dacheux and F. Dacheux, "Protein secretion in the epididymis," in The Epididymis. From Molecules to Clinical Pratice, pp. 151-168, Kluwer Academic/Plenum Publishers, New York, NY, USA, 2002.

[22] J. L. Dacheux, M. Belghazi, Y. Lanson, and F. Dacheux, "Human epididymal secretome and proteome," Molecular and Cellular Endocrinology, vol. 250, no. 1-2, pp. 36-42, 2006.

[23] C. Kirchhoff, "Gene expression in the epididymis," International Review of Cytology, vol. 188, pp. 133-202, 1999.

[24] C. M. Rodríguez, J. L. Kirby, and B. T. Hinton, "Regulation of gene transcription in the epididymis," Reproduction, vol. 122, no. 1, pp. 41-48, 2001.

[25] A. H. Horan and J. M. Bedford, "Development of the fertilizing ability of spermatozoa in the epididymis of the Syrian hamster," Journal of Reproduction and Fertility, vol. 30, no. 3, pp. 417-423, 1972.
[26] J. L. Dacheux and M. Paquignon, "Relations between the fertilizing ability, motility and metabolism of epididymal spermatozoa," Reproduction Nutrition Developpement, vol. 20, no. 4 A, pp. 1085-1099, 1980.

[27] J.-L. Dacheux, J. Luc Gatti, and F. Dacheux, "Contribution of epididymal secretory proteins for spermatozoa maturation," Microscopy Research and Technique, vol. 61, no. 1, pp. 7-17, 2003.

[28] R. Sullivan, "Interaction between sperm and epididymal secretory proteins," in The Male Gamete: From Basic to Clinical Applications, pp. 130-136, Cache River Press, Vienna, Ill, USA, 1999.

[29] A. Mújica, F. Navarro-Garcí, E. O. Hernández-González, and M. D. L. Juárez-Mosqueda, "Perinuclear theca during spermatozoa maturation leading to fertilization," Microscopy Research and Technique, vol. 61, no. 1, pp. 76-87, 2003.

[30] E. Sahin, A. M. Petrunkina, D. Waberski, R. A. P. Harrison, and E. Töpfer-Petersen, "Control of bull sperm cell volume during epididymal maturation," Reproduction, Fertility and Development, vol. 21, no. 3, pp. 469-478, 2009.

[31] R. C. Jones and R. N. Murdoch, "Regulation of the motility and metabolism of spermatozoa for storage in the epididymis of eutherian and marsupial mammals," Reproduction, Fertility and Development, vol. 8, no. 4, pp. 553-568, 1996.

[32] R. Sullivan, G. Frenette, and J. Girouard, "Epididymosomes are involved in the acquisition of new sperm proteins during epididymal transit," Asian Journal of Andrology, vol. 9, no. 4, pp. 483-491, 2007.

[33] B. Robaire and N. A. Henderson, "Actions of $5 \alpha$-reductase inhibitors on the epididymis," Molecular and Cellular Endocrinology, vol. 250, no. 1-2, pp. 190-195, 2006.

[34] M. K. Holland and B. Nixon, "The specificity of epididymal secretory proteins," Journal of Reproduction and Fertility, vol. 53, pp. 197-210, 1998.

[35] R. S. Viger and B. Robaire, "The mRNAs for the steroid $5 \alpha$ reductase isozymes, types 1 and 2, are differentially regulated in the rat epididymis," Journal of Andrology, vol. 17, no. 1, pp. 27-34, 1996.

[36] R. A. Hess, Q. Zhou, R. Nie et al., "Estrogens and epididymal function," Reproduction, Fertility and Development, vol. 13, no. 4, pp. 273-283, 2001.

[37] R. A. Hess, D. Bunick, and J. M. Bahr, "Sperm, a source of estrogen," Environmental Health Perspectives, vol. 103, supplement 7, pp. 59-62, 1995.

[38] R. A. Hess, D. Bunick, K.-H. Lee et al., "A role for oestrogens in the male reproductive system," Nature, vol. 390, no. 6659, pp. 509-512, 1997.

[39] R. A. Hess, "Oestrogen in fluid transport in efferent ducts of the male reproductive tract," Reviews of Reproduction, vol. 5, no. 2, pp. 84-92, 2000.

[40] B. Bilińska, B. Wiszniewska, K. Kosiniak-Kamysz et al., "Hormonal status of male reproductive system: androgens and estrogens in the testis and epididymis. In vivo and in vitro approaches," Reproductive Biology, vol. 6, supplement 1, pp. 43-58, 2006.

[41] J. M. Bedford, "Effects of elevated temparature on the epididymis and testis: experimental studies," Advances in Experimental Medicine and Biology, vol. 286, pp. 19-32, 1991.

[42] J. M. Bedford and R. Yanagimachi, "Epididymal storage at abdominal temperature reduces the time required for capacitation of hamster spermatozoa," Journal of Reproduction and Fertility, vol. 91, no. 2, pp. 403-410, 1991. 
[43] M. Jara, P. Esponda, and R. Carballada, "Abdominal temperature induces region-specific p53-independent apoptosis in the cauda epididymidis of the mouse," Biology of Reproduction, vol. 67, no. 4, pp. 1189-1196, 2002.

[44] C. Reyes-Moreno, J. Laflamme, G. Frenette, M.-A. Sirard, and R. Sullivan, "Spermatozoa modulate epididymal cell proliferation and protein secretion in vitro," Molecular Reproduction and Development, vol. 75, no. 3, pp. 512-520, 2008.

[45] C. N. Graves, M. B. Ferguson, and O. C. Miller, "Internal scrotal temperature of dairy bulls as determined by telemetry," Journal of Dairy Science, vol. 53, no. 12, pp. 1703-1708, 1970.

[46] R. G. Wales, J. C. Wallace, and I. G. White, "Composition of bull epididymal and testicular fluid," Journal of Reproduction and Fertility, vol. 12, no. 1, pp. 139-144, 1966.

[47] J. M. Rifkin and G. E. Olson, "Characterization of maturation-dependent extrinsic proteins of the rat sperm surface," Journal of Cell Biology, vol. 100, no. 5, pp. 15821591, 1985.

[48] B. M. Phelps, P. Primakoff, D. E. Koppel, M. G. Low, and D. G. Myles, "Restricted lateral diffusion of PH-20, a PIanchored sperm membrane protein," Science, vol. 240, no. 4860, pp. 1780-1782, 1988.

[49] M. Manin, P. Lecher, A. Martinez, S. Tournadre, and C. Jean, "Exportation of mouse vas deferens protein, a protein without a signal peptide, from mouse vas deferens epithelium: a model of apocrine secretion," Biology of Reproduction, vol. 52, no. 1, pp. 50-62, 1995.

[50] G. Frenette, C. Lessard, E. Madore, M. A. Fortier, and R. Sullivan, "Aldose reductase and macrophage migration inhibitory factor are associated with epididymosomes and spermatozoa in the bovine epididymis," Biology of Reproduction, vol. 69, no. 5, pp. 1586-1592, 2003.

[51] R. Eickhoff, B. Wilhelm, H. Renneberg et al., "Purification and characterization of macrophage migration inhibitory factor as a secretory protein from rat epididymis: evidences for alternative release and transfer to spermatozoa," Molecular Medicine, vol. 7, no. 1, pp. 27-35, 2001.

[52] R. Eickhoff, C. Baldauf, H.-W. Koyro et al., "Influence of macrophage migration inhibitory factor (MIF) on the zinc content and redox state of protein-bound sulphydryl groups in rat sperm: indications for a new role of MIF in sperm maturation," Molecular Human Reproduction, vol. 10, no. 8, pp. 605-611, 2004.

[53] G. Frenette, C. Légaré, F. Saez, and R. Sullivan, "Macrophage migration inhibitory factor in the human epididymis and semen," Molecular Human Reproduction, vol. 11, no. 8, pp. 575-582, 2005.

[54] F. Saez, G. Frenette, and R. Sullivan, "Epididymosomes and prostasomes: their roles in posttesticular maturation of the sperm cells," Journal of Andrology, vol. 24, no. 2, pp. 149-154, 2003.

[55] R. Yanagimachi, Y. Kamiguchi, and K. Mikamo, "Maturation of spermatozoa in the epididymis of the Chinese hamster," American Journal of Anatomy, vol. 172, no. 4, pp. 317-330, 1985.

[56] M. W. Fornes, A. Barbieri, and J. C. Cavicchia, "Morphological and enzymatic study of membrane-bound vesicles from the lumen of the rat epididymis," Andrologia, vol. 27, no. 1, pp. 1-5, 1995.

[57] G. Frenette and R. Sullivan, "Prostasome-like particles are involved in the transfer of P25b from the bovine epididymal fluid to the sperm surface," Molecular Reproduction and Development, vol. 59, no. 1, pp. 115-121, 2001.

[58] P. Sutovsky, R. Moreno, J. Ramalho-Santos, T. Dominko, W. E. Thompson, and G. Schatten, "A putative, ubiquitindependent mechanism for the recognition and elimination of defective spermatozoa in the mammalian epididymis," Journal of Cell Science, vol. 114, part 9, pp. 1665-1675, 2001.

[59] G. Frenette, C. Lessard, and R. Sullivan, "Selected proteins of "prostasome-like particles" from epididymal cauda fluid are transferred to epididymal caput spermatozoa in bull," Biology of Reproduction, vol. 67, no. 1, pp. 308-313, 2002.

[60] C. Légaré, B. Bérubé, F. Boué et al., "Hamster sperm antigen P26h is a phosphatidylinositol-anchored protein," Molecular Reproduction and Development, vol. 52, no. 2, pp. 225-233, 1999.

[61] G. Aumüller, B. Wilhelm, and J. Seitz, "Apocrine secretion: fact or artifact?" Annals of Anatomy, vol. 181, no. 5, pp. 437446, 1999.

[62] G. Aumueller and G. Adler, "Experimental studies of apocrine secretion in the dorsal prostate epithelium of the rat," Cell and Tissue Research, vol. 198, no. 1, pp. 145-158, 1979.

[63] V. K. Bajpai, A. C. Shipstone, and R. Kumar, "Ultrastructure of the epididymal epithelium of rhesus monkey (Macaca mulatta)," Acta Europaea Fertilitatis, vol. 16, no. 3, pp. 207217, 1985.

[64] Y. Agrawal and T. Vanha-Perttula, "Electron microscopic study of the secretion process in bovine reproductive organs," Journal of Andrology, vol. 9, no. 5, pp. 307-316, 1988.

[65] L. Hermo, H. I. Adamali, and S. Andonian, "Immunolocalization of CA II and H+V-ATPase in epithelial cells of the mouse and rat epididymis," Journal of Andrology, vol. 21, no. 3, pp. 376-391, 2000.

[66] A. Morales and J. C. Cavicchia, "Release of cytoplasmic apical protrusions from principal cells of the cat epididymis, an electron microscopic study," Tissue and Cell, vol. 23, no. 4, pp. 505-513, 1991.

[67] L. Hermo and D. Jacks, "Nature's ingenuity: bypassing the classical secretory route via apocrine secretion," Molecular Reproduction and Development, vol. 63, no. 3, pp. 394-410, 2002.

[68] R. Sullivan, F. Saez, J. Girouard, and G. Frenette, "Role of exosomes in sperm maturation during the transit along the male reproductive tract," Blood Cells, Molecules, and Diseases, vol. 35, no. 1, pp. 1-10, 2005.

[69] G. Frenette, J. Girouard, and R. Sullivan, "Comparison between epididymosomes collected in the intraluminal compartment of the bovine caput and cauda epididymidis," Biology of Reproduction, vol. 75, no. 6, pp. 885-890, 2006.

[70] P. Vernet, R. J. Aitken, and J. R. Drevet, "Antioxidant strategies in the epididymis," Molecular and Cellular Endocrinology, vol. 216, no. 1-2, pp. 31-39, 2004.

[71] C. Kirchhoff and G. Hale, "Cell-to-cell transfer of glycosylphosphatidylinositol-anchored membrane proteins during sperm maturation," Molecular Human Reproduction, vol. 2, no. 3, pp. 177-184, 1996.

[72] C. H. Yeung, T. G. Cooper, and E. Nieschlag, "Human epididymal secreted protein CD52 on ejaculated spermatozoa: correlations with semen characteristics and the effect of its antibody," Molecular Human Reproduction, vol. 3, no. 12, pp. 1045-1051, 1997.

[73] H. Chen, G. Griffiths, D. S. Galileo, and P. A. Martin-DeLeon, "Epididymal SPAM1 is a marker for sperm maturation in the mouse," Biology of Reproduction, vol. 74, no. 5, pp. 923-930, 2006. 
[74] M. H. Jones, P. M. Davey, H. Aplin, and N. A. Affara, "Expression analysis, genomic structure, and mapping to $7 \mathrm{q} 31$ of the human sperm adhesion molecule gene SPAM1," Genomics, vol. 29, no. 3, pp. 796-800, 1995.

[75] E. A. Evans, H. Zhang, and P. A. Martin-DeLeon, "SPAM1 (PH-20) protein and mRNA expression in the epididymides of humans and macaques: utilizing laser microdissection/RTPCR," Reproductive Biology and Endocrinology, vol. 1, article no. 54, 2003.

[76] G. Morin, C. Lalancette, R. Sullivan, and P. Leclerc, "Identification of the bull sperm $\mathrm{p} 80$ protein as a $\mathrm{PH}-20$ ortholog and its modification during the epididymal transit," Molecular Reproduction and Development, vol. 71, no. 4, pp. 523-534, 2005.

[77] G. Morin, R. Sullivan, I. Laflamme, C. Robert, and P. Leclerc, "SPAM1 isoforms from two tissue origins are differentially localized within ejaculated bull sperm membranes and have different roles during fertilization," Biology of Reproduction, vol. 82, no. 2, pp. 271-281, 2010.

[78] R. Jones, A. Ma, S.-T. Hou, R. Shalgi, and L. Hall, “Testicular biosynthesis and epididymal endoproteolytic processing of rat sperm surface antigen 2B1," Journal of Cell Science, vol. 109, part 10, pp. 2561-2570, 1996.

[79] H. Rejraji, P. Vernet, and J. R. Drevet, "GPX5 is present in the mouse caput and cauda epididymidis lumen at three different locations," Molecular Reproduction and Development, vol. 63, no. 1, pp. 96-103, 2002.

[80] E. Kim, M. Yamashita, T. Nakanishi et al., "Mouse sperm lacking ADAM1b/ADAM2 fertilin can fuse with the egg plasma membrane and effect fertilization," Journal of Biological Chemistry, vol. 281, no. 9, pp. 5634-5639, 2006.

[81] H. Nishimura, E. Kim, T. Nakanishi, and T. Baba, "Possible function of the ADAM1a/ADAM2 fertilin complex in the appearance of ADAM3 on the sperm surface," Journal of Biological Chemistry, vol. 279, no. 33, pp. 34957-34962, 2004.

[82] J. S. Oh, C. Han, and C. Cho, "ADAM7 is associated with epididymosomes and integrated into sperm plasma membrane," Molecules and Cells, vol. 28, no. 5, pp. 441-446, 2009.

[83] R. Sullivan and G. Bleau, "Interaction of isolated components from mammalian sperm and egg," Gamete Research, vol. 12, no. 1, pp. 101-116, 1985.

[84] B. Berube and R. Sullivan, "Inhibition of in vivo fertilization by active immunization of male hamsters against a $26-\mathrm{kDa}$ sperm glycoprotein," Biology of Reproduction, vol. 51, no. 6, pp. 1255-1263, 1994.

[85] F. Boué and R. Sullivan, "Cases of human infertility are associated with the absence of $\mathrm{P} 34 \mathrm{H}$, an epididymal sperm antigen," Biology of Reproduction, vol. 54, no. 5, pp. 10181024, 1996.

[86] S. Begin, B. Berube, F. Boue, and R. Sullivan, "Comparative immunoreactivity of mouse and hamster sperm proteins recognized by an anti-P26h hamster sperm protein," Molecular Reproduction and Development, vol. 41, no. 2, pp. 249-256, 1995.

[87] S. Parent, L. Lefievre, Y. Brindle, and R. Sullivan, "Bull subfertility is associated with low levels of a sperm membrane antigen," Molecular Reproduction and Development, vol. 52, no. 1, pp. 57-65, 1999.

[88] C. Lessard, S. Parent, P. Leclerc, J. L. Bailey, and R. Sullivan, "Cryopreservation alters the levels of the bull sperm surface protein P25b," Journal of Andrology, vol. 21, no. 5, pp. 700707,2000 .
[89] N. Lamontagne, C. Légaré, C. Gaudreault, and R. Sullivan, "Identification and characterization of $\mathrm{P} 31 \mathrm{~m}$, a novel sperm protein in Cynomolgus monkey (Macaca fascicularis)," Molecular Reproduction and Development, vol. 59, no. 4, pp. 431-441, 2001.

[90] C. A. Mawson and M. I. Fischer, "Zinc content of the genital organs of the rat," Nature, vol. 167, no. 4256, p. 859, 1951.

[91] A. Srivastava, A. R. Chowdhury, and B. S. Setty, "Testicular regulation and sub-cellular distribution of zinc in the epididymis and vas deferens of rhesus monkey (Macaca mulatta)," Acta Endocrinologica, vol. 113, no. 3, pp. 440-449, 1986.

[92] L. Rajendran and K. Simons, "Lipid rafts and membrane dynamics," Journal of Cell Science, vol. 118, part 6, pp. 10991102, 2005.

[93] S. Shadan, P. S. James, E. A. Howes, and R. Jones, "Cholesterol efflux alters lipid raft stability and distribution during capacitation of boar spermatozoa," Biology of Reproduction, vol. 71, no. 1, pp. 253-265, 2004.

[94] D. A. Brown and E. London, "Structure and function of sphingolipid- and cholesterol-rich membrane rafts," Journal of Biological Chemistry, vol. 275, no. 23, pp. 17221-17224, 2000.

[95] D. F. Legler, M.-A. Doucey, P. Schneider, L. Chapatte, F. C. Bender, and C. Bron, "Differential insertion of GPI-anchored GFPs into lipid rafts of live cells," FASEB Journal, vol. 19, no. 1, pp. 73-75, 2005.

[96] X. Liang, A. Nazarian, H. Erdjument-Bromage, W. Bornmann, P. Tempst, and M. D. Resh, "Heterogeneous fatty acylation of Src family kinases with polyunsaturated fatty acids regulates raft localization and signal transduction," Journal of Biological Chemistry, vol. 276, no. 33, pp. 3098730994, 2001.

[97] J. E. Parks and R. H. Hammerstedt, "Development changes occurring in the lipids of ram epididymal spermatozoa plasma membrane," Biology of Reproduction, vol. 32, no. 3, pp. 653-668, 1985.

[98] J. Girouard, G. Frenette, and R. Sullivan, “Compartmentalization of proteins in epididymosomes coordinates the association of epididymal proteins with the different functional structures of bovine spermatozoa," Biology of Reproduction, vol. 80, no. 5, pp. 965-972, 2009.

[99] W. M. Fornes, M. A. Sosa, F. Bertini, and M. H. Burgos, "Vesicles in rat epididymal fluid. Existence of two populations differing in ultrastructure and enzymatic composition," Andrologia, vol. 27, no. 4, pp. 233-237, 1995.

[100] G. J. Frenette, O. D’Amours, N. Allard, L. Tessier, and R. Sullivan, "Characterization of two distinct populations of epididymosomes collected in the intraluminal compartment of the bovine cauda epididymis," Biology of Reproduction, vol. 83, no. 3, pp. 473-480, 2010.

[101] H. D. Moore, L. A. Samayawardhena, and I. A. Brewis, "Sperm maturation in vitro: co-culture of spermatozoa and epididymal epithelium," Journal of Reproduction and Fertility, vol. 53, pp. 23-31, 1998.

[102] C. Reyes-Moreno, M. Boilard, R. Sullivan, and M.-A. Sirard, "Characterization of secretory proteins from cultured cauda epididymal cells that significantly sustain bovine sperm motility in vitro," Molecular Reproduction and Development, vol. 63, no. 4, pp. 500-509, 2002.

[103] C. Reyes-Moreno, A. Gagnon, R. Sullivan, and M.-A. Sirard, "Addition of specific metabolites to bovine epididymal cell 
culture medium enhances survival and motility of cryopreserved sperm," Journal of Andrology, vol. 21, no. 6, pp. 876$886,2000$.

[104] A. Gagnon, R. Sullivan, and M.-A. Sirard, "Epididymal epithelial cells cultured in vitro prolong the motility of bovine sperm," Journal of Andrology, vol. 21, no. 6, pp. 842$847,2000$.

[105] M. A. Akhondi, C. Chapple, and H. D. M. Moore, "Prolonged survival of human spermatozoa when co-incubated with epididymal cell cultures," Human Reproduction, vol. 12, no. 3, pp. 514-522, 1997.

[106] A. Ijaz, R. D. Lambert, and M.-A. Sirard, "In vitro-cultured bovine granulosa and oviductal cells secrete sperm motilitymaintaining factor(s)," Molecular Reproduction and Development, vol. 37, no. 1, pp. 54-60, 1994.

[107] S. Lapointe, J.-F. Bilodeau, D. Lemieux, E. Asselin, M. Fortier, and M.-A. Sirard, "Epithelial and stromal uterine cells cultured in vitro protect bovine sperm from hydrogen peroxide," Theriogenology, vol. 54, no. 3, pp. 355-369, 2000.

[108] C. Reyes-Moreno, M. Boilard, R. Sullivan, and M.-A. Sirard, "Characterization and identification of epididymal factors that protect ejaculated bovine sperm during in vitro storage," Biology of Reproduction, vol. 66, no. 1, pp. 159-166, 2002.

[109] M. Bouthillier, G. Bleau, A. Chapdelaine, and K. D. Roberts, "Distribution of steroid sulfotransferase in the male hamster reproductive tract," Biology of Reproduction, vol. 31, no. 5, pp. 936-941, 1984.

[110] K. D. Roberts, "Sterol sulfates in the epididymis: synthesis and possible function in the reproductive process," Journal of Steroid Biochemistry, vol. 27, no. 1-3, pp. 337-341, 1987.

[111] N. Gamage, A. Barnett, N. Hempel et al., "Human sulfotransferases and their role in chemical metabolism," Toxicological Sciences, vol. 90, no. 1, pp. 5-22, 2006.

[112] G. Frenette, P. Leclerc, O. D'Amours, and R. Sullivan, "Estrogen sulfotransferase is highly expressed along the bovine epididymis and is secreted into the intraluminal environment," Journal of Andrology, vol. 30, no. 5, pp. 580$589,2009$.

[113] T. Kobayashi, T. Kaneko, Y. Iuchi et al., "Localization and physiological implication of aldose reductase and sorbitol dehydrogenase in reproductive tracts and spermatozoa of male rats," Journal of Andrology, vol. 23, no. 5, pp. 674-683, 2002.

[114] G. Frenette, M. Thabet, and R. Sullivan, "Polyol pathway in human epididymis and semen," Journal of Andrology, vol. 27, no. 2, pp. 233-239, 2006.

[115] P. J. Oates, "Polyol pathway and diabetic peripheral neuropathy," International Review of Neurobiology, vol. 50, pp. 325392, 2002.

[116] R. N. Murdoch and I. G. White, "Studies of the metabolism of human spermatozoa," Journal of Reproduction and Fertility, vol. 16, no. 3, pp. 351-361, 1968.

[117] B. R. Bloom and B. Bennett, "Mechanism of a reaction in vitro associated with delayed-type hypersensitivity," Science, vol. 153 , no. 3731 , pp. 80-82, 1966.

[118] P. R. Somanath, S. L. Jack, and S. Vijayaraghavan, "Changes in sperm glycogen synthase kinase-3 serine phosphorylation and activity accompany motility initiation and stimulation," Journal of Andrology, vol. 25, no. 4, pp. 605-617, 2004.

[119] Z. Huang, K. Myers, B. Khatra, and S. Vijayaraghavan, "Protein 14-3-3 $\zeta$ binds to protein phosphatase PP1 $\gamma 2$ in bovine epididymal spermatozoa," Biology of Reproduction, vol. 71, no. 1, pp. 177-184, 2004.
[120] G. Ronquist, I. Brody, A. Gottfries, and B. Stegmayr, "An $\mathrm{Mg} 2+$ and $\mathrm{Ca} 2+$-stimulated adenosine triphosphatase in human prostatic fluid: part I," Andrologia, vol. 10, no. 4, pp. 261-272, 1978.

[121] G. Ronquist, I. Brody, A. Gottfries, and B. Stegmayr, "An $\mathrm{Mg} 2+$ and $\mathrm{Ca} 2+$-stimulated adenosine triphosphatase in human prostatic fluid-Part II," Andrologia, vol. 10, no. 6, pp. 427-433, 1978.

[122] B. K. Davis, "Uterine fluid proteins bind sperm cholesterol during capacitation in the rabbit," Experientia, vol. 38, no. 9, pp. 1063-1064, 1982.

[123] H. Breitbart and S. Rubinstein, "Characterization of Mg2+and Ca2+-ATPase activity in membrane vesicles from ejaculated ram seminal plasma," Archives of Andrology, vol. 9, no. 2, pp. 147-157, 1982.

[124] G. Arienti, E. Carlini, A. M. De Cosmo, P. Di Profio, and C. A. Palmerini, "Prostasome-like particles in stallion semen," Biology of Reproduction, vol. 59, no. 2, pp. 309-313, 1998.

[125] M. W. Fornes and J. C. De Rosas, "Interactions between rat epididymal epithelium and spermatozoa," Anatomical Record, vol. 231, no. 2, pp. 193-200, 1991.

[126] Y. Agrawal and T. Vanha-Perttula, "Effect of secretory particles in bovine seminal vesicle secretion on sperm motility and acrosome reaction," Journal of Reproduction and Fertility, vol. 79, no. 2, pp. 409-419, 1987.

[127] G. Sahlen, O. Nilsson, A. Larsson, L. Carlsson, B. J. Norlén, and G. Ronquist, "Secretions from seminal vesicles lack characteristic markers for prostasomes," Upsala Journal of Medical Sciences, vol. 115, no. 2, pp. 107-112, 2010.

[128] G. Ronquist and B. O. Nilsson, Prostasomes, 81, Portland Press, London, UK, 2002.

[129] K. G. Ronquist, G. Ronquist, L. Carlsson, and A. Larsson, "Human prostasomes contain chromosomal DNA," Prostate, vol. 69, no. 7, pp. 737-743, 2009.

[130] G. Arvidson, G. Ronquist, G. Wikander, and A.-C. Ojteg, "Human prostasome membranes exhibit very high cholesterol/phospholipid ratios yielding high molecular ordering," Biochimica et Biophysica Acta, vol. 984, no. 2, pp. 167-173, 1989.

[131] I. A. Rooney, A. Davies, D. Griffiths, J. D. Williams, M. Davies, and S. Meri, "The complement-inhibiting protein, protectin (CD59 antigen), is present and functionally active on glomerular epithelial cells," Clinical and Experimental Immunology, vol. 83, no. 2, pp. 251-256, 1991.

[132] I. A. Rooney, J. P. Atkinson, E. S. Krul et al., "Physiologic relevance of the membrane attack complex inhibitory protein CD59 in human seminal plasma: CD59 is present on extracellular organelles (prostasomes), binds cell membranes, and inhibits complement-mediated lysis," Journal of Experimental Medicine, vol. 177, no. 5, pp. 1409-1420, 1993.

[133] I. A. Rooney, J. E. Heuser, and J. P. Atkinson, "GPI-anchored complement regulatory proteins in seminal plasma: an analysis of their physical condition and the mechanisms of their binding to exogenous cells," Journal of Clinical Investigation, vol. 97, no. 7, pp. 1675-1686, 1996.

[134] B. Stegmayr and G. Ronquist, "Promotive effect on human sperm progressive motility by prostasomes," Urological Research, vol. 10, no. 5, pp. 253-257, 1982.

[135] L. Carlsson, G. Ronquist, M. Stridsberg, and L. Johansson, "Motility stimulant effects of prostasome inclusion in swimup medium on cryopreserved human spermatozoa," Archives of Andrology, vol. 38, no. 3, pp. 215-221, 1997.

[136] N. L. Cross and P. Mahasreshti, "Proteasome fraction of human seminal plasma prevents sperm from becoming 
acrosomally responsive to the agonist progesterone," Archives of Andrology, vol. 39, no. 1, pp. 39-44, 1997.

[137] F. S. Esch, N. C. Ling, and P. Bohlen, "Primary structure of PDC-109, a major protein constituent of bovine seminal plasma," Biochemical and Biophysical Research Communications, vol. 113, no. 3, pp. 861-867, 1983.

[138] N. G. Seidah, P. Manjunath, and J. Rochemont, "Complete amino acid sequence of BSP-A3 from bovine seminal plasma. Homology to PDC-109 and to the collagen-binding domain of fibronectin," Biochemical Journal, vol. 243, no. 1, pp. 195203, 1987.

[139] J. J. Calvete, K. Mann, L. Sanz, M. Raida, and E. TöpferPetersen, "The primary structure of BSP-30K, a major lipid-, gelatin-, and heparin-binding glycoprotein of bovine seminal plasma," FEBS Letters, vol. 399, no. 1-2, pp. 147-152, 1996.

[140] L. Desnoyers and P. Manjunath, "Major proteins of bovine seminal plasma exhibit novel interactions with phospholipid," Journal of Biological Chemistry, vol. 267, no. 14, pp. 10149-10155, 1992.

[141] I. Thérien, R. Moreau, and P. Manjunath, "Major proteins of bovine seminal plasma and high-density lipoprotein induce cholesterol efflux from epididymal sperm," Biology of Reproduction, vol. 59, no. 4, pp. 768-776, 1998.

[142] D. E. Wolf, S. S. Hagopian, and S. Ishijima, "Changes in sperm plasma membrane lipid diffusibility after hyperactivation during in vitro capacitation in the mouse," Journal of Cell Biology, vol. 102, no. 4, pp. 1372-1377, 1986.

[143] R. A. van Gestel, I. A. Brewis, P. R. Ashton, J. B. Helms, J. F. Brouwers, and B. M. Gadella, "Capacitation-dependent concentration of lipid rafts in the apical ridge head area of porcine sperm cells," Molecular Human Reproduction, vol. 11, no. 8, pp. 583-590, 2005.

[144] N. Okamura, S. Kiuchi, M. Tamba et al., "A porcine homolog of the major secretory protein of human epididymis, HE1, specifically binds cholesterol," Biochimica et Biophysica Acta, vol. 1438, no. 3, pp. 377-387, 1999.

[145] S. Fouchecourt, S. Metayer, A. Locatelli, F. Dacheux, and J.L. Dacheux, "Stallion epididymal fluid proteome: qualitative and quantitative characterization; secretion and dynamic changes of major proteins," Biology of Reproduction, vol. 62, no. 6, pp. 1790-1803, 2000.

[146] P. K. Schoff, J. Cheetham, and H. A. Lardy, "Adenylate kinase activity in ejaculated bovine sperm flagella," Journal of Biological Chemistry, vol. 264, no. 11, pp. 6086-6091, 1989.

[147] S. I. Moskovtsev, K. Jarvi, C. Légaré, R. Sullivan, and J. B. M. Mullen, "Epididymal $\mathrm{P} 34 \mathrm{H}$ protein deficiency in men evaluated for infertility," Fertility and Sterility, vol. 88, no. 5, pp. 1455-1457, 2007.

[148] A. A. Moura, H. Koc, D. A. Chapman, and G. J. Killian, "Identification of proteins in the accessory sex gland fluid associated with fertility indexes of dairy bulls: a proteomic approach," Journal of Andrology, vol. 27, no. 2, pp. 201-211, 2006.

[149] T. C. McCauley, H. Zhang, M. E. Bellin, and R. L. Ax, "Purification and characterization of fertility-associated antigen (FAA) in bovine seminal fluid," Molecular Reproduction and Development, vol. 54, no. 2, pp. 145-153, 1999.

[150] A. A. Moura, D. A. Chapman, H. Koc, and G. J. Killian, "Proteins of the cauda epididymal fluid associated with fertility of mature dairy bulls," Journal of Andrology, vol. 27, no. 4, pp. 534-541, 2006.

[151] O. D'Amours, G. Frenette, M. Fortier, P. Leclerc, and R. Sullivan, "Proteomic comparison of detergent-extracted sperm proteins from bulls with different fertility indexes," Reproduction, vol. 139, no. 3, pp. 545-556, 2010.

[152] D. W. Erikson, A. L. Way, D. A. Chapman, and G. J. Killian, "Detection of osteopontin on Holstein bull spermatozoa, in cauda epididymal fluid and testis homogenates, and its potential role in bovine fertilization," Reproduction, vol. 133, no. 5, pp. 909-917, 2007.

[153] S. Ronkko, R. Lahtinen, and T. Vanha-Perttula, "Phospholipases A2 in the reproductive system of the bull," International Journal of Biochemistry, vol. 23, no. 5-6, pp. 595-603, 1991.

[154] H. Breitbart and B. Spungin, "The biochemistry of the acrosome reaction," Molecular Human Reproduction, vol. 3, no. 3, pp. 195-202, 1997.

[155] M. S. Riffo and M. Párraga, "Role of phospholipase A2 in mammalian sperm-egg fusion: development of hamster oolemma fusibility by lysophosphatidylcholine," Journal of Experimental Zoology, vol. 279, no. 1, pp. 81-88, 1997.

[156] Y. Y. Yuan, W. Y. Chen, Q. X. Shi et al., "Zona pellucida induces activation of phospholipase A2 during acrosomal exocytosis in guinea pig spermatozoa," Biology of Reproduction, vol. 68, no. 3, pp. 904-913, 2003.

[157] S. Bao, D. J. Miller, Z. Ma et al., "Male mice that do not express Group VIA Phospholipase A2 produce spermatozoa with impaired motility and have greatly reduced fertility," Journal of Biological Chemistry, vol. 279, no. 37, pp. 3819438200, 2004.

[158] C. Schöneck, J. Braun, and R. Einspanier, "Sperm viability is influenced in vitro by the bovine seminal protein aSFP: effects on motility, mitochondrial activity and lipid peroxidation," Theriogenology, vol. 45, no. 3, pp. 633-642, 1996.

[159] N. Susan, R.-S. Ana, W. T. Dixon, G. R. Foxcroft, and M. K. Dyck, "Seminal plasma proteins as potential markers of relative fertility in boars," Journal of Andrology, vol. 31, no. 2, pp. 188-200, 2010.

[160] P. Manjunath and I. Thérien, "Role of seminal plasma phospholipid-binding proteins in sperm membrane lipid modification that occurs during capacitation," Journal of Reproductive Immunology, vol. 53, no. 1-2, pp. 109-119, 2002.

[161] P. Manjunath, S. Soubeyrand, L. Chandonnet, and K. D. Roberts, "Major proteins of bovine seminal plasma inhibit phospholipase A2," Biochemical Journal, vol. 303, part 1, pp. 121-128, 1994.

[162] A. Jauhiainen and T. Vanha-Perttula, " $\alpha$-L-Fucosidase in the reproductive organs and seminal plasma of the bull," Biochimica et Biophysica Acta, vol. 880, no. 1, pp. 91-95, 1986.

[163] J. G. Alvarez and B. T. Storey, "Differential incorporation of fatty acids into and peroxidative loss of fatty acids from phospholipids of human spermatozoa," Molecular Reproduction and Development, vol. 42, no. 3, pp. 334-346, 1995.

[164] W. Stillwell and S. R. Wassall, "Docosahexaenoic acid: membrane properties of a unique fatty acid," Chemistry and Physics of Lipids, vol. 126, no. 1, pp. 1-27, 2003.

[165] A. Saalmann, S. Mnz, K. Ellerbrock, R. Ivell, and C. Kirchhoff, "Novel sperm-binding proteins of epididymal origin contain four fibronectin type II-modules," Molecular Reproduction and Development, vol. 58, no. 1, pp. 88-100, 2001.

[166] W. Cao, L. Haig-Ladewig, G. L. Gerton, and S. B. Moss, "Adenylate kinases 1 and 2 are part of the accessory structures in the mouse sperm flagellum," Biology of Reproduction, vol. 75, no. 4, pp. 492-500, 2006.

[167] R. Gibbons, S. A. Adeoya-Osiguwa, and L. R. Fraser, "A mouse sperm decapacitation factor receptor is phosphatidylethanolamine-binding protein 1," Reproduction, vol. 130, no. 4, pp. 497-508, 2005. 
[168] B. Nixon, D. A. MacIntyre, L. A. Mitchell, G. M. Gibbs, M. O'Bryan, and R. J. Aitken, "The identification of mouse sperm-surface-associated proteins and characterization of their ability to act as decapacitation factors," Biology of Reproduction, vol. 74, no. 2, pp. 275-287, 2006.

[169] P. F. Watson, "Recent developments and concepts in the cryopreservation of spermatozoa and the assessment of their post-thawing function," Reproduction, Fertility, and Development, vol. 7, no. 4, pp. 871-891, 1995.

[170] J. L. Bailey, J.-F. Bilodeau, and N. Cormier, "Minireview: semen cryopreservation in domestic animals: a damaging and capacitating phenomenon," Journal of Andrology, vol. 21, no. 1, pp. 1-7, 2000.

[171] P. F. Watson, "The causes of reduced fertility with cryopreserved semen," Animal Reproduction Science, vol. 60-61, pp. 481-492, 2000. 

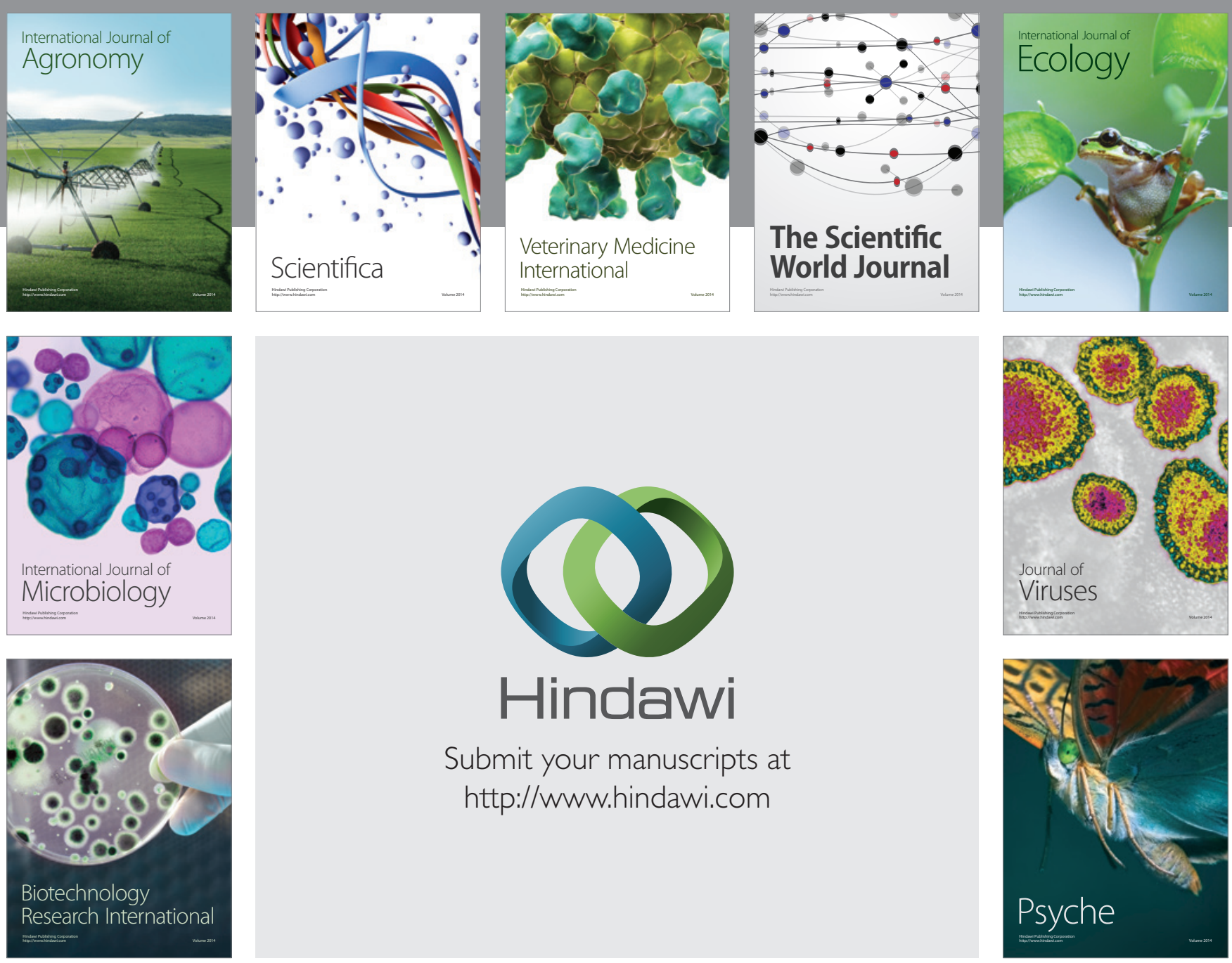

Submit your manuscripts at

http://www.hindawi.com
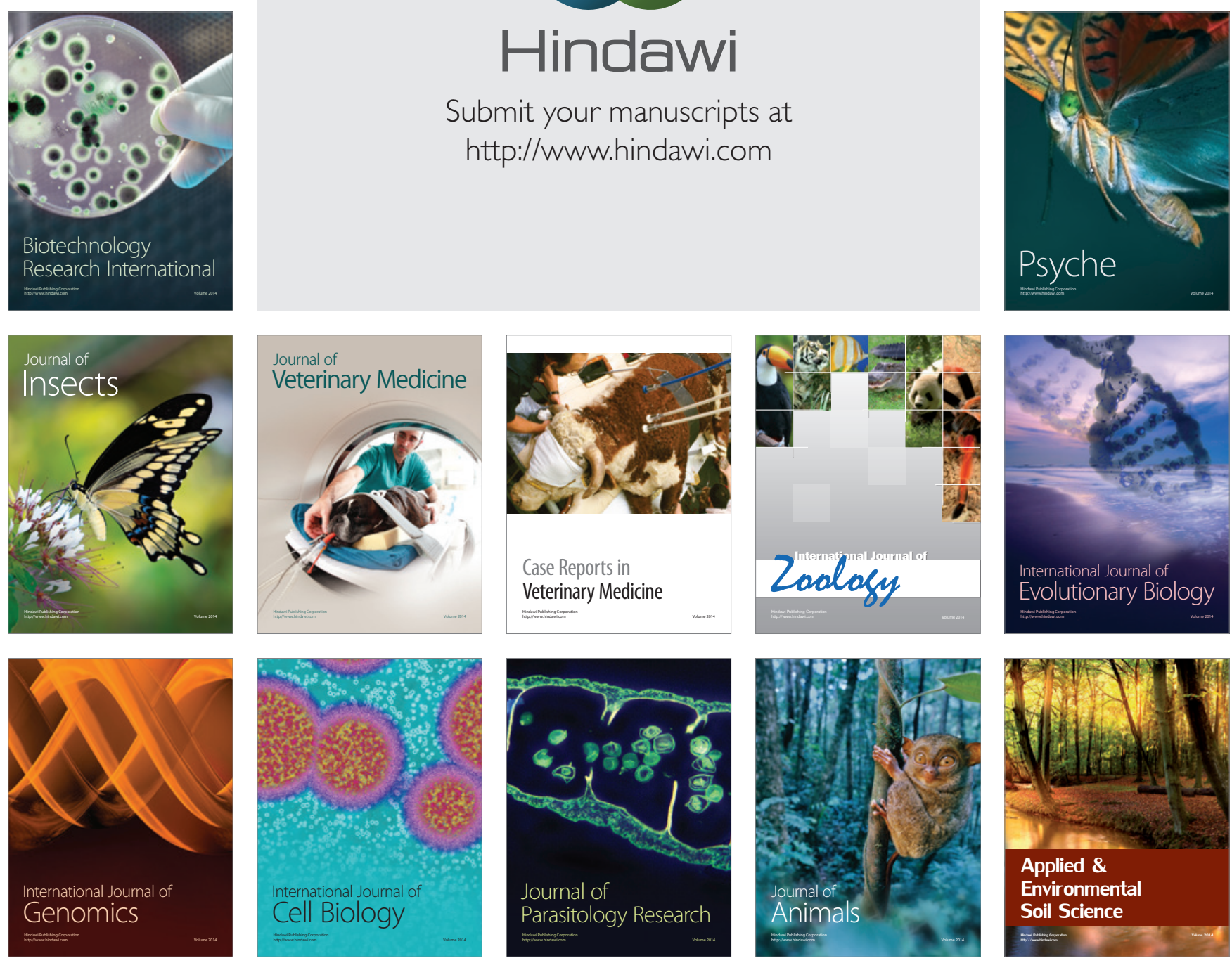